\title{
Radiological anatomy after pyloroplasty
}

D. K. M. TOYE, J. F. K. HUTtON, AND J. AleXANDER Williams

From the General Hospital, Birmingham

SUMMARY The radiological anatomy of the pyloro-duodenal area after pyloroplasty is described. The deformity produced by pyloroplasty is shown in the patient with a normal pylorus and duodenum and in the patient with a duodenal ulcer and stenosis. From a study of 24 asymptomatic patients after pyloroplasty it is possible to recognize the radiological features that indicate a successful operation.

In the United Kingdom vagotomy and pyloroplasty is fast becoming the most popular operation in the treatment of chronic duodenal ulceration. While most patients are cured, approximately $10 \%$ continue to complain of some form of indigestion. When the patient has continued dyspepsia, clinicians usually suspect that either the operation has failed to cure the ulcer or that the pyloroplasty drainage has been ineffective; they then turn to radiologists for help in confirming their suspicions. However, radiologists have been reluctant to play a major role in the evaluation of these patients, partly because they have accepted the view that radiology can play no part in the evaluation of duodenal ulcer activity and partly because it was thought impossible to exclude ulceration in the presence of pyloroduodenal deformity. Further difficulties arose from lack of familiarity with the postoperative anatomy, particularly in those patients without complications. The present study is an attempt to clarify the changes in anatomy brought about by a Heineke-Mickulicz pyloroplasty and to indicate the radiological features of a successful operation.

The Effect of Pyloroplasty on the Normal Pyloric Canal

THEORETICAL EFFECT

The simplest form of pyloroplasty and the one still most widely used (Heineke-Mikulicz pyloroplasty) involves a longitudinal incision in the line of the gut 2 to $5 \mathrm{~cm}$ either side of the pylorus. The upper and lower edges of the centre of this incision are then drawn apart and the proximal and distal ends brought together in the centre $\stackrel{C}{\subseteq}$ so that the incision is closed in the transverse axis of the bowel. The effect of drawing the ends 3 of the incision towards the centre is to produce 8 a pouch at the site of the suture line and so traction $₹$ on the longitudinal muscle fibres at either end of 0 the incision. This traction produces a constriction or 'sling' proximal and distal to the pouch. This theoretical anatomical model is shown in Fig. 1 and should lead to four structures that $\%$ we might expect to recognize radiologically. $N$ Proceeding from the antrum distally, these

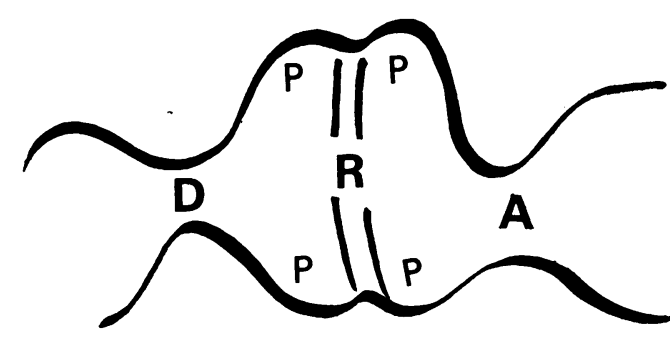

Fig. 1 Diagram of theoretical landmarks to be expected on radiographs after pyloroplasty. $\mathbf{P P}=$ Pouches $\quad \mathbf{D}=$ Duodenal constriction $\mathbf{R}=$ Ridge $\quad \mathbf{A}=$ Antral constriction 


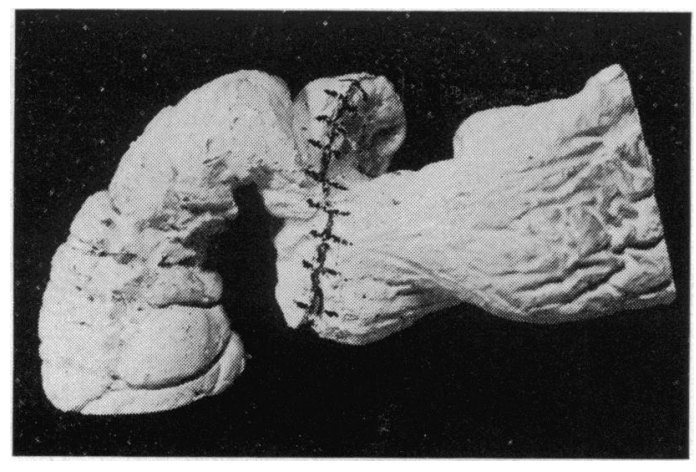

Fig. 2a Photograph of plaster cast of pyloroduodenal channel after postmortem pyloroplasty. Anterior view showing position of suture line, pouches, and slings. The position of the ridge was identified on the posterior aspect.

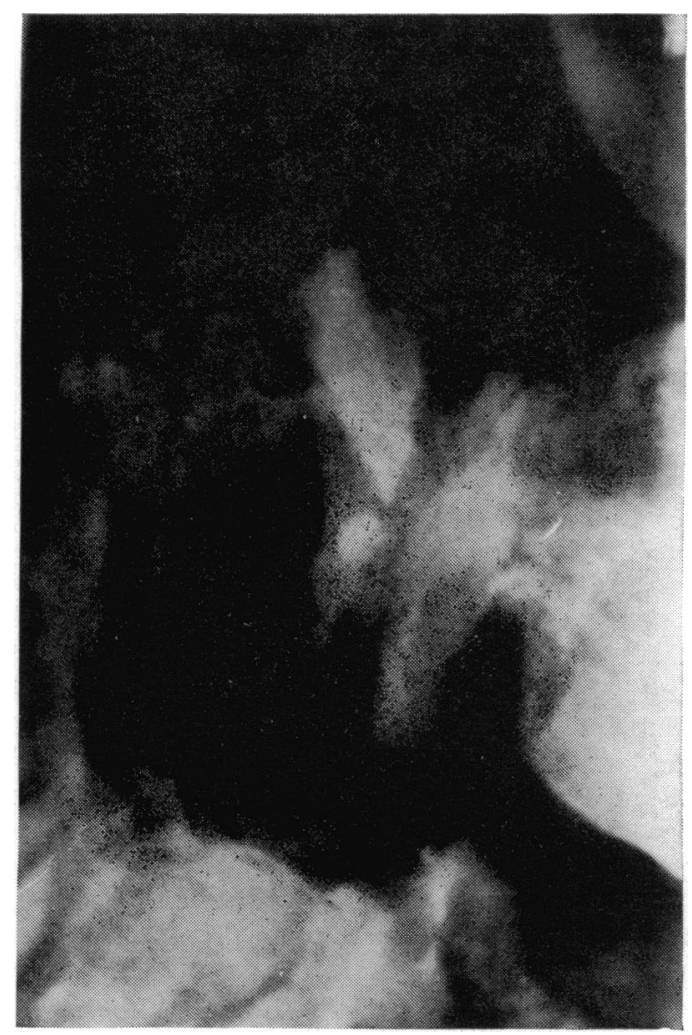

Fig. 2b Radiographs of pyloroplasty channel in postmortem specimen. The channel is partly filled with barium and clearly shows the four structures described in Figure 1. are: (1) the antral constriction; (2) a pouch at the site of the suture line which will continue on its posterior aspect; (3) a ridge or bar formed by the ring of pyloric muscle; and, distally (4) the duodenal constriction. Furthermore, it follows that, in theory, the longer the pyloroplasty incision the greater will be the size of the pouch and the greater the degree of constriction produced by the sling effect.

\section{CADAVER STUDY}

The theoretical hypothesis was tested by a postmortem study in which a pyloroplasty was performed on a normal duodenum. This area was then filled with barium and a radiograph taken. It was finally filled with plaster of Paris and a cast formed. Examination of the cast and its comparison with the radiograph supported by the anatomical description previously proposed (Figures 2a and b).

\section{CLINICAL STUDY}

Six patients were studied in whom a HeinekeMikulicz pyloroplasty had been performed on a duodenum that was previously radiologically and anatomically normal. These patients had hiatus hernia (3), gastric ulcer (2), and no demonstrable gastric disease (1). The patients were all asymptomatic at the time of study after pyloroplasty.

The radiological findings after pyloroplasty in these patients again confirmed the expectations from the theoretical model (Figures $3 a$ and $b$ ).

\section{The Effect of Pyloroplasty on Abnormal Anatomy}

When the normal anatomy of the pyloroduodenal area is distorted by fibrosis, ulceration, and oedema the radiological anatomy after pyloroplasty will differ from that after pyloroplasty on the normal pylorus.

CLINICAL STUDY

Eighteen patients were studied after vagotomy and Heineke-Mikulicz pyloroplasty for demonstrable duodenal ulceration or deformity due to chronic ulcer disease. At the time of study after pyloroplasty all patients were free of symptoms and all have since remained cured of ulcer dyspepsia.

In these patients, in whom there was originally an ulcer crater but very little deformity, the postoperative radiological pattern appeared similar to that seen in those patients with pyloroplasty on the normal pylorus described above. However, when there had been gross duodenal 


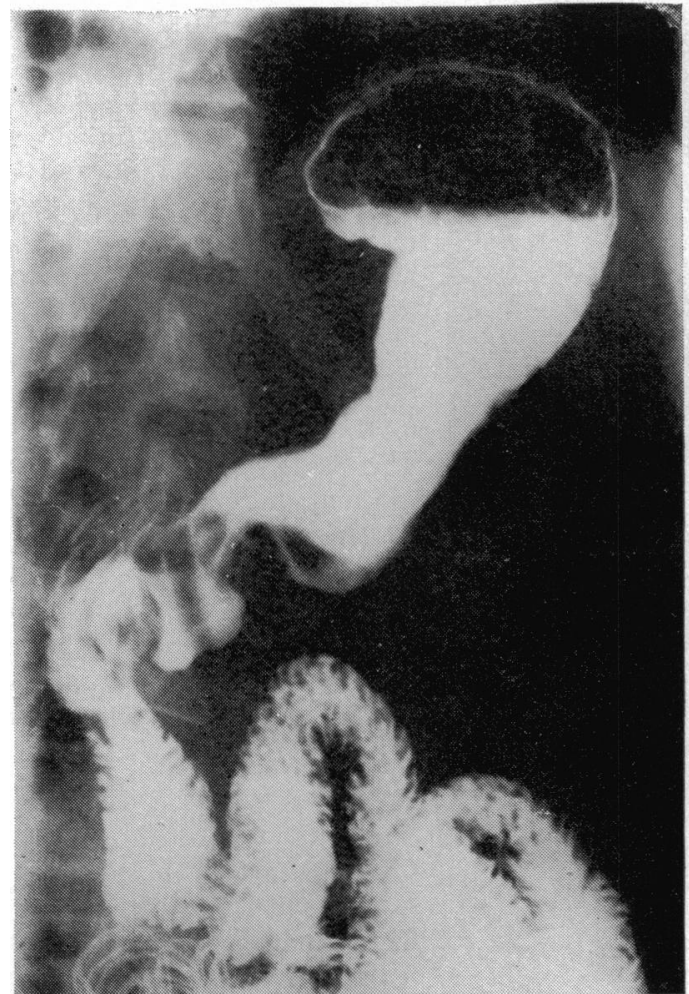

FIG. 3a

Fig. 3 Normal pyloroplasty appearances.

(a) Note the antral sling and the ridge across the pyloroplasty pouches. The stomach is emptying rapidly into the small bowel and the antrum appears bowed upwards.

(b) Pouches are present above and below the channel and the duodenum sling is well demonstrated.

deformity or oedema, variations from this pattern were observed.

\section{Outline}

Some pouching was always seen at the pyloroplasty. However, the inferior or superior pouch was sometimes absent, depending on whether the pyloroplasty incision had passed along the lower or upper border of the first part of the duodenum. When the posterior wall of the duodenum was fixed as a result of scarring, the mobile stomach was pulled distally over the duodenum and the pouch was sometimes seen distal to the pyloric bar.

\section{Mucosal pattern}

The clear demonstration of the mucosal pattern in the pyloroduodenal area is of particular importance in patients after pyloroplasty but is not always easy to achieve. In 24 asymptomatic patients studied after pyloroplasty a

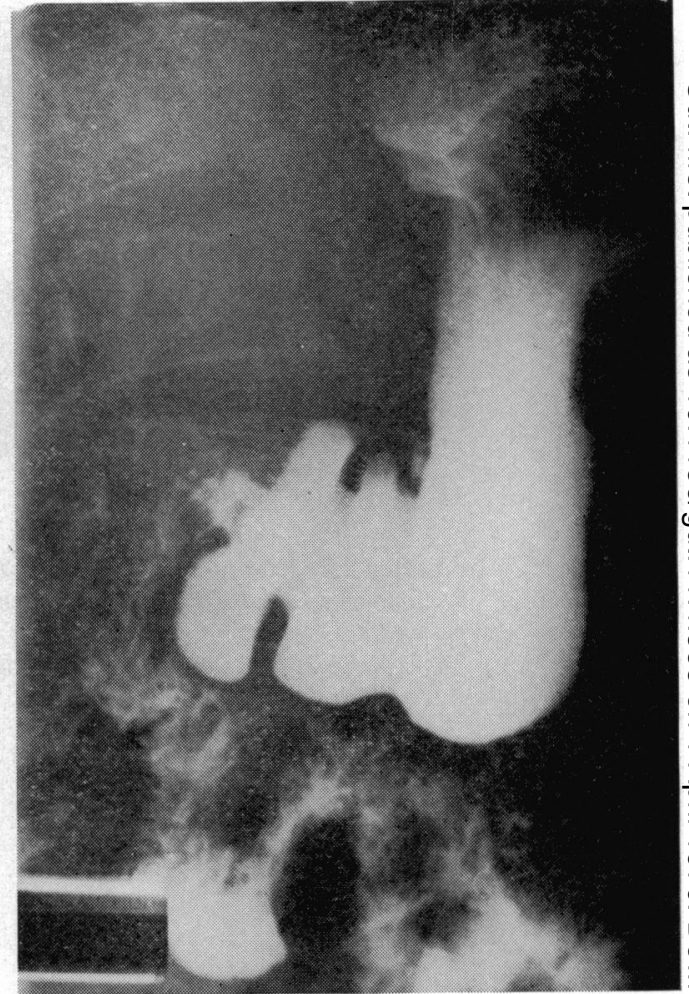

FIG. $3 b$.

satisfactory mucosal pattern was achieved in 19 $(79 \%)$ at the first attempt. This percentage could be improved by repeating the more difficult examinations.

The new lines of traction created by the pyloroplasty produce a straightening in the mucosal folds. It would be expected that the folds on the posterior wall would run in the transverse axis of the bowel and those on the anterior 을 wall would be drawn along the long axis of $D$ the bowel. Superimposition of anterior and posterior folds occasionally gives a criss-cross $N$ appearance in the mucosal pattern. This might 0 suggest the radiation of folds from the chronic $\tilde{O}$ ulcer and lead to an erroneous diagnosis of $N_{\omega}^{N}$ recurrent ulceration (Figure 4).

\section{Disappearance of the ulcer crater}

It is accepted radiological teaching that it is impossible to evaluate radiologically the healing of a duodenal ulcer. However, after pyloroplasty $\overrightarrow{\mathbb{D}}$ and when a posterior ulcer was previously $\frac{\mathcal{O}}{\mathbb{Q}}$ demonstrated it may be possible to show that the mucosa of the posterior wall is now intact and so infer healing of the ulcer (Figure 5).

In our series of 18 patients with duodenal ulcer studied after pyloroplasty there were 10 in whom an active posterior wall ulcer had been de- $\underset{?}{\rightleftharpoons}$ monstrated before operation and in eight of these it was now possible to demonstrate the presence of a normal mucosal pattern on the 


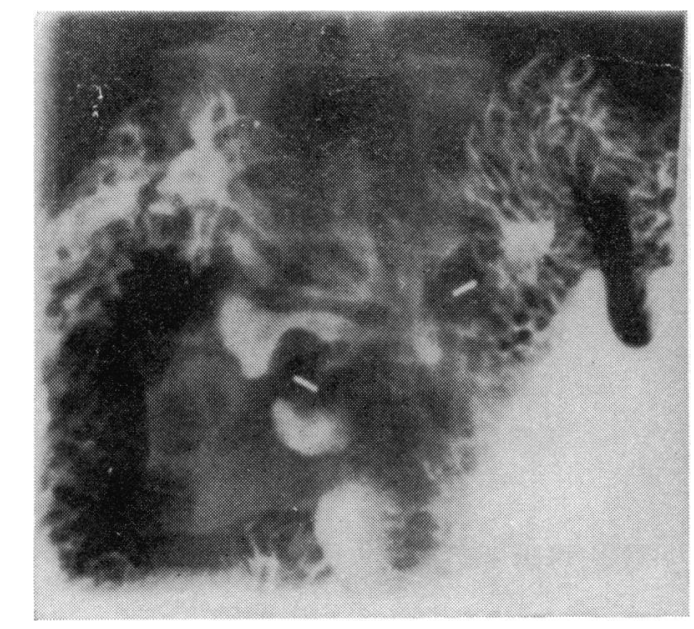

Fig. 4 Mucosal relief of the channel. The folds apparently converge and the resultant density may at first sight be mistaken for an ulcer crater. This appearance is due to superimposition of anterior and posterior folds. (Note also markers at either end of ridge.)

posterior wall. In a further five patients who had preoperative duodenal scarring but no ulcer crater, the postoperative radiographs showed a normal mucosal pattern in the pyloroplasty channel. The postoperative barium studies did not give sufficiently clear definition to permit evaluation in three.

\section{Free drainage and the absence of retention}

The 'sphincteric' effect of the pyloric muscle is abolished by pyloroplasty and if the pyloroplasty is successful there should be no resting gastric juice in a stomach of normal size. In all our patients the postoperative examination showed that there was no appreciable residue, a normal sized stomach, and a rapid passage of barium into the duodenum (Fig. 3).

\section{Discussion}

Others who have studied the radiological appearances of the pyloro-duodenal area after pyloroplasty have described the characteristic pouch deformity (Burhenne, 1964; Riach, 1968). It has been pointed out that ciné-radiographic studies demonstrate that these pouches exhibit muscular movement and can therefore be differentiated from recurrent ulcer craters. (Bloch and Wolf, 1965; Gleeson and Ellis, 1968). All these authors have stressed the difficulties in diagnosing recurrent ulceration.
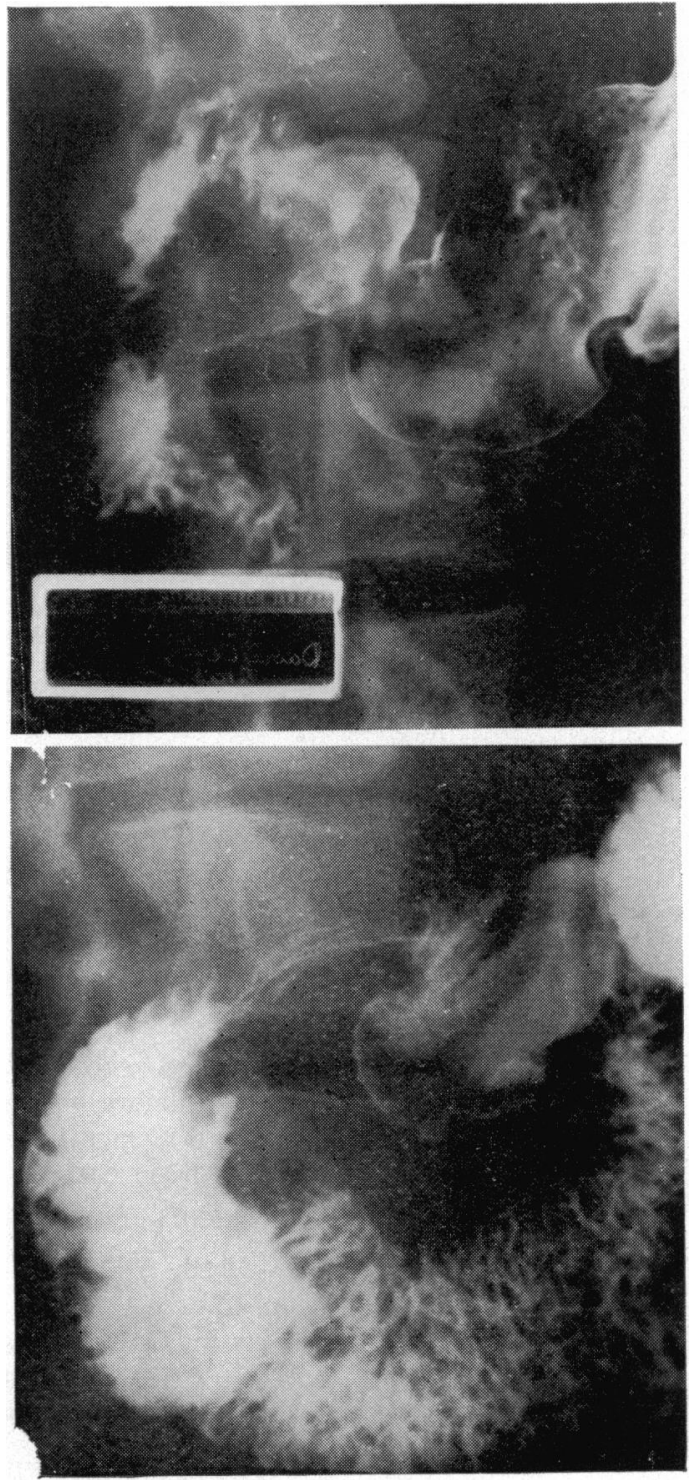

Fig. 5 Disappearance of ulcer crater.

(Above) Crater in duodenal cap before operation. (Below) One of a series of mucosal pattern films of the pyloroplasty channel showing that the crater has disappeared.

We believe that, with a knowledge of the expected postoperative anatomical features and good pictures of the mucosal pattern in the pyloro-duodenal channel, it is possible to recognize the normal and against this background to evaluate the abnormal. In a subsequent paper we will demonstrate the abnormal and assess the value of radiology in evaluating postoperative dypsepsia. 
Bloch, C., and Wolf, B. S. (1965). Gastroduodenal channel after pyloroplasty and vagotomy: cineradiographic study. Radiology, 84, 43-51

Burhenne, H. J. (1964). Roentgen anatomy and terminology of gastric surgery. Amer. J. Roentgenol., 91, 731-743

Gleeson, J., and Ellis, H. (1968). Cineradiographic studies after vagotomy and pyloroplasty. Brit.J. Surg., 55, 385-386

Riach, I. C. F. (1968). Personal communication.

\section{The March 1970 Issue}

\section{THE MARCH 1970 ISSUE CONTAINS THE FOLLOWING PAPERS}

\section{0-1970: Three Editors THOMAS HUNT}

Two cases of 'pancreatic cholera' with features of peptide-secreting adenomatosis of the pancreas W. SIRCUS, P. W. BRUNT, R. J. WALKER, W. P. SMALL, C. W. A. FALCONER, AND CHRISTINE G. THOMSON

Bio-assay evidence of abnormal secretin-like and gastrin-like activity in tumour and blood in cases of 'choleraic diarrhoea' I. G. M. CLEATOR, CHRISTINE G. THOMSON, W. SIRCUS, AND MIRANDA COOMBES

Malabsorption and subtotal villous atrophy secondary to pulmonary and intestinal tuberculosis W. P. FUNG, K. K. TAN, S. F. YU, AND K. M. KHO

Cell loss from small intestinal mucosa: a morphological study I. J. PINK, D. N. CROFT, AND B. CREAMER

IgM turnover in Crohn's disease $\mathrm{K}$. BIRGER JENSEN, NIELS GOLTERMANN, STIG JARNUM, BENT WEEKE, AND HENRIK WESTERGAARD

The diagnostic value of mucosubstances in rectal biopsies from patients with ulcerative colitis and Crohn's disease M. I. FILIPE AND IAN DAWSON

The results of ileorectal anastomosis at St Mark's Hospital from 1953-1968 w. N. W. BAKER

Sodium dependency of $\mathrm{L}$-alanine absorption in canine Thiry-Vella loops BERTRAM FLESHLER AND RALPH A. NELSON
Portal hypertension caused by partial nodular transformation of the liver M. CLASSEN, $K$. ELSTER, H. J. PESCH, AND L. DEMLING

Intestinal absorption of carnosine and its constituent amino acids in man A. M. ASATOOR, J. K. BANDOH, A. F. LANT, M. D. MILNE, AND F. NAVAB

A study of total serum alkaline phosphatase activity in men following partial gastrectomy J. AMBLER, A. G. GREEN, AND C. N. PULVERTAFT

Psychiatric disorders after surgery for duodenal ulcer M. C. MASON AND C. G. CLARK

Experiences with data processing to separate the images in pancreatic scanning D. CHARLESWORTH, H. J. TESTA, B. R. PULLAN, AND H. BRUCE TORRANCE

Modification of polyethylene glycol estimation suitable for use with small mammals J. M. BOULTER AND H. B. MCMICHAEL

Progress Report: Disorders of the myenteric plexus BARBARA SMITH

Progress Report: Liver biopsy in the diagnosis of cirrhosis P. J. SCHEUER

Notes and Activities

Copies are still available and may be obtained from the PUBLISHING MANAGER, BRITISH MEDICAL ASSOCIATION, TAVISTOCK SQUARE, W.C.1. price 17s. 6D. 